\title{
Institutional analysis defining the crucial factors for scaling low-emissions rice production: Evidence from Bangladesh
}

\author{
H. Trang Vu ${ }^{1 *}$, Katherine M. Nelson ${ }^{1 *}$, Syed Samsuzzaman², Saidur M. Rahman ${ }^{3}$, Mamunur Rashid ${ }^{4}$, \\ Ahmad Salahuddin ${ }^{5}$, Bjoern Ole Sander ${ }^{1}$
}

${ }^{1}$ International Rice Research Institute, Hanoi, Vietnam, https://orcid.org/0000-0001-9242-246X, https://orcid.org/0000-0002-7967-6147

\author{
${ }^{2}$ North Bengal Institute of Development Studies (NIDS), Rangpur, Bangladesh \\ ${ }^{3}$ Bangladesh Agricultural University, Mymensingh, Bangladesh \\ ${ }^{4}$ Rangpur Dinajpur Rural Service, Rangpur, Bangladesh \\ ${ }^{5}$ International Rice Research Institute, Dhaka, Bangladesh \\ *Co-first authors \\ **Corresponding author contact information: Dr. Katherine M. Nelson, Institutional Rice Research \\ Institute, Hanoi, Vietnam, k.nelson@irri.org
}

\begin{abstract}
This article provides a comprehensive institutional analysis to better understand the key conditions and incentives relevant for the uptake of alternate wetting and drying (AWD) - a climate-smart irrigation practice in Bangladesh. Practicing AWD in rice production can reduce water consumption by $30 \%$ and mitigate methane emissions by $30-70 \%$ without yield penalty. Primary research was conducted in Rangpur, Rajshahi, Mymensingh, and Sherpur Divisions. The analysis depicts the dynamic among the stakeholders involved in outscaling AWD using the Net-Map tool, and demonstrates the influence of irrigation management systems in the selected catchment areas and the impacts of AWD in rice farming. Findings reveal that AWD-practicing farmers, pump owners, and the Upazila Irrigation Committee are the three most powerful influencers for outscaling AWD. The pre-paid irrigation system significantly improves water efficiency and cost-effectiveness when practising AWD. Additionally, AWD leads to a lower frequency of pumping resulting in reduced costs compared to the continuous-flooding practice. Finally, the results guide the formulation of recommendations to create favourable conditions for AWD outscaling, which contributes to reducing greenhouse gas emissions and advancing sustainable rice production in Bangladesh.
\end{abstract}

\section{Keywords}

Climate-smart agriculture; low-emissions agriculture; alternate wetting and drying; irrigation management; sustainable rice production; climate change mitigation 


\section{Introduction}

Agriculture contributes about 15.33\% to Bangladesh's Gross Domestic Product (Bangladesh Ministry of Finance, 2014), in which rice dominates the crop sector with an average of $71 \%$ share of output, $79 \%$ of the total cropped area, and over $72 \%$ of the total irrigated area (Bangladesh Bureau of Statistics, 2015). Rice is grown in three seasons, in which the Boro (post-monsoon) rice accounts for approximately $60 \%$ of total rice production (Bangladesh Bureau of Statistics, 2015). Over 78\% of Boro rice is irrigated using groundwater resources. It is estimated that producing one kilogram of paddy rice consumes 3,000-5,000 litres of water (Bangladesh Rice Research Institute, 2017). The practice of rice production in continuous flooding conditions contributes significantly to shrinking groundwater resources. On the other hand, irrigated rice production contributes more greenhouse gas (GHG) emissions than any other grain crop, accounting for $7.6 \%$ of the total global methane $\left(\mathrm{CH}_{4}\right)$ emissions from anthropogenic sources ${ }^{1}$.

Reducing GHG emissions and water consumption in rice production can be achieved through the practice of alternate wetting and drying (AWD). With AWD, the rice field is dried intermittently during specific growth periods and water is maintained at a safe level (not below $15 \mathrm{~cm}$ below soil surface). Practising AWD can reduce the amount of water to under $2000 \mathrm{~L} / \mathrm{kg}$ of rice, saving water by about 38\% without compromising rice yields (Rejesus, Palis, Rodriguez, Lampayan, \& Bouman, 2011) and increasing water productivity by $17 \%$ compared with continuously flooded irrigation (Tan, et al., 2011). In addition, AWD can effectively mitigate $\mathrm{CH}_{4}$ emissions by $30-70 \%$ (Price et al. 2013). Concerning costs, AWD could save up to $€ 56.4$ million in electricity or $€ 78.8$ million in fuel or 30 litres of diesel/ha from reduced irrigation amount and frequency (Miah, 2009).

Nonetheless, most of the current literature on the application of AWD in producing Boro rice - to name a few: Alam et al. (2009); Hasan et al. (2016); Hossain (2013); Husain et al. (2009); Mishra et al. (1990); Mishra et al. (2015); Price, et al. (2013); and Rahman and Angelsen (2011) - focused majorly on the effects on water use efficiency, rice yield, and the probability of using water-saving technologies. Considerably less research has focused on the institutional factors that influence the uptake of AWD.

Considering the water-saving and GHG mitigation potential, AWD has been promoted in Bangladesh through government initiatives with research and development partnerships since 2004 with the International Rice Research Institute (IRRI) playing a central role. The public sector, private sector and non-governmental organizations (NGOs) have since introduced AWD into their programs and conducted validations and pilots to disseminate this practice. The dissemination of AWD received high commitment by key organizations. However, a clear dynamic of the process across relevant stakeholders has not been well documented. Many organizations only got as far as piloting and validating this technology but fell short when it came to scaling out the technology. 
Working on the assumption that the spread of AWD on a wider scale is driven by key stakeholders and power structures, an enabling policy environment, and incentives that are relevant for the uptake of the technology, we conducted a comprehensive institutional analysis to better understand the contextual factors influencing adoption using the following steps:

1) Define key stakeholders, roles, and social influence through stakeholder mapping;

2) Characterize the rules/norms governing water pricing and irrigation;

3) Analyse irrigation governance; and

4) Compare the economic incentives of AWD in terms of irrigation frequency and costs.

Specifically, the objectives of the study are to identify the key stakeholders and their power structure influencing AWD outscaling; define the irrigation payment schemes that enable and optimize the effectiveness of AWD technology; and demonstrate the economic and environmental incentives of AWD in rice farming. Although the study focuses on conditions in Bangladesh, the results are relevant to rice production in other South Asian and South East Asian contexts.

\section{Methodology}

\section{$2.1 \quad$ Research samples and data collection tools}

The research was carried out in 14 villages in three divisions across Northern Bangladesh, namely Rangpur, Rajshahi, and Mymensingh divisions (see the map of locations in Figure 1). The selection of survey areas was based on the presence of AWD demonstrations.

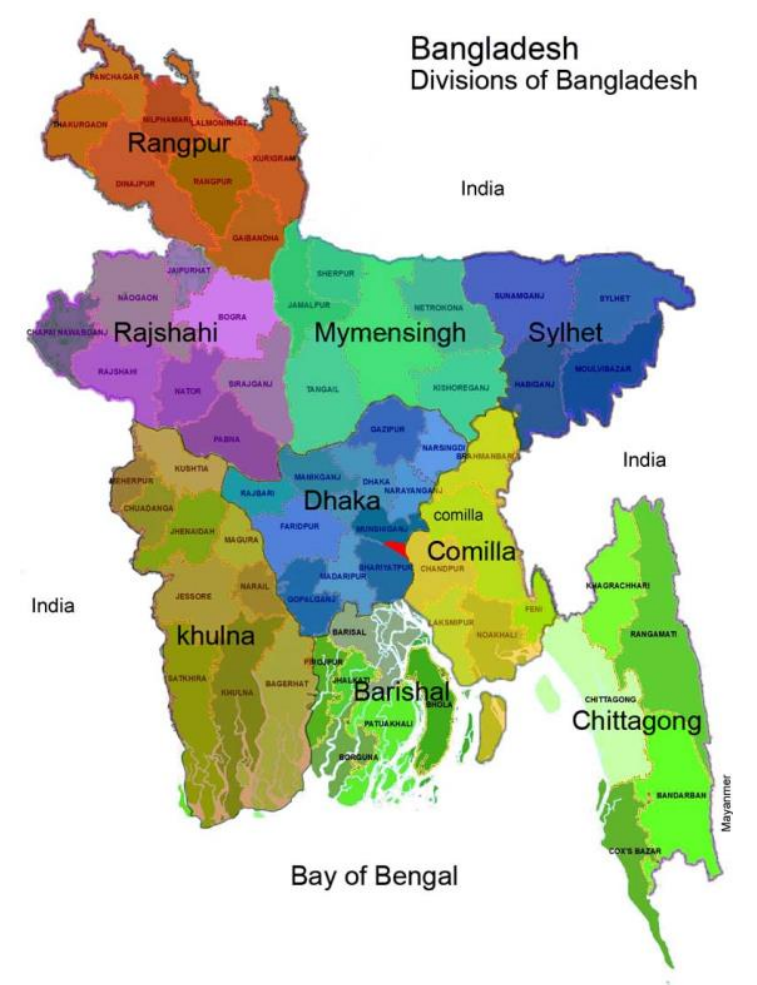

Figure 1: Map of Bangladesh. Source: https://www.mediabangladesh.net/map-of-bangladesh/

In total, four data collection periods were conducted with a total of 802 participants, including farmers who applied AWD on their fields, farmers who used the continuous flooding irrigation method, pump 
owners, governmental officials, and representatives of organizations involved in irrigation management. The sample sizes in different data collection times are described in detail in Table 1 below.

Data were collected using multiple methods: desk review of available research papers and reports, focus group discussions (FGD), key informant interviews (KII), and surveys. The fieldwork was conducted with practitioners that apply AWD and those that continuously flood their fields for comparison. The research was conducted in accordance with national ethical standards, as well as those of the 1964 Helsinki Declaration and later amendments ${ }^{3}$. As this was a non-interventional study, it did not require prior approval from an ethics committee; however, participants were explained the purpose of the study, and were informed that their participation was voluntary and informed consent was obtained from all individual participants involved in the study.

Table 1: Study locations, times, and sample sizes

\begin{tabular}{|c|c|c|c|c|c|}
\hline $\begin{array}{l}\text { Study } \\
\text { locations - }\end{array}$ & District/Upazila/Union/Village & \multicolumn{3}{|c|}{ Sample sizes } & \multirow{2}{*}{$\begin{array}{c}\text { Total } \\
\text { sample } \\
\text { size }\end{array}$} \\
\hline \multicolumn{2}{|c|}{ Rangpur and Rajshahi Divisions - three separate data collection times } & $\begin{array}{l}\text { May } \\
2018\end{array}$ & $\begin{array}{c}\text { January } \\
2019\end{array}$ & $\begin{array}{l}\text { May } \\
2019\end{array}$ & \\
\hline \multirow{7}{*}{ Rangpur } & Rangpur/Taraganj/Hariakuti/Baroghoria Chapra & 29 & 30 & 64 & 123 \\
\hline & $\begin{array}{l}\text { Nilphamari/Nilphamari } \\
\text { Sadar/Polashbari/Polashbari/Matorpara } \\
\text { and } \\
\text { Nilphamari/Kishoreganj Sadar/Kishoreganj/Kalkutipara }\end{array}$ & 52 & 39 & 65 & 156 \\
\hline & Kurigram/Rajarhat/Rajarhat/Haridagga & 34 & 38 & 34 & 106 \\
\hline & Gaibandha/Gaibandha Sadar/Horinshinha & 29 & & & 29 \\
\hline & $\begin{array}{l}\text { Thakurgaon/Thakurgaon Sadar/Goreya/Araji Matigara } \\
\text { (Goreya) }\end{array}$ & & 32 & 40 & 72 \\
\hline & Panchagarh/Boda/Jholoi Salsiri/Vullipara & & 22 & 25 & 47 \\
\hline & Lalmonirhat/Aditmari/Sharpukur/Sharpukur Balatary & & 12 & 32 & 44 \\
\hline \multirow{2}{*}{ Rajshahi } & Rajshahi/Tanor & 19 & 26 & 38 & 83 \\
\hline & Noagaon/Manda/Kusumbag/Naradangi & 16 & 22 & 32 & 70 \\
\hline \multicolumn{6}{|c|}{ Mymensingh and Sherpur Divisions - one data collection in 2015} \\
\hline \multirow[t]{3}{*}{ Mymensingh } & \multicolumn{4}{|l|}{ Muktagacha/Dulla/Joynakanda } & 15 \\
\hline & \multicolumn{4}{|l|}{ Tarakanda/Bakshimul } & 12 \\
\hline & \multicolumn{4}{|l|}{ Trishal/Boilorcharpara } & 15 \\
\hline \multirow[t]{2}{*}{ Sherpur } & \multicolumn{4}{|l|}{ Nokla/4 No. Gordan/Runygao } & 15 \\
\hline & \multicolumn{4}{|l|}{ Nalitabari/Jugania/Uttar Kapasia } & 15 \\
\hline \multicolumn{5}{|c|}{ TOTAL SAMPLE SIZE } & 802 \\
\hline
\end{tabular}




\subsection{Stakeholder mapping tool}

The participatory Net-Map tool was adopted for the stakeholder analysis in this study (Schiffer, 2007). This is an interview technique used to generate a map of stakeholders based on their connections and power relations (Schiffer, 2007). It aids the visualization, understanding, and discussion of the processes that involve multiple actors whose interaction affect outcomes. In the process of making a Net-Map, participants are facilitated to examine both official and unofficial interactions among stakeholders, hence fostering the understanding of the group's approach, strategies, and activities. For an outside observer, this tool demonstrates how to understand and monitor the complex processes among stakeholders.

Information was obtained by group consensus, commonalities and differences of interviewees. Upon nominating an actor to be included, respondents would explain why that actor was important to add. Next, relation flows and power flows were drawn among the actors. Then influence scores were attributed to each actor card, with 0 signifying that an actor has no influence and 5 signifying the highest degree of influence. Finally, each actor was ranked according to their level of active support for outscaling AWD. See Figure 2 below for the visual depiction resulting from the exercise that shows which stakeholders are important for outscaling AWD.

Using the participatory Net-Map tool, the qualitative information was collected through a review of literature, focus group discussion (FGD) with farmers and pump owners and key informant interviews (KII) with Upazila (sub-district) culture officers (UAO) of the Department of Agricultural Extension (DAE) and executive engineers of Bangladesh Agriculture Development Corporation (BADC/BMDA). A total of eight FGDs were conducted across the study locations (one FGD with AWD group including pump owners in each village as given in Table 1). Similarly, a total of ten KIIs were conducted across the study locations (one KII with UAO each in eight Upazilas that include AWD village groups and two executive engineers of Rangpur and Rajshahi districts on sampling basis as given in Table 1). This method captures the relevant information from the farmers with AWD and government duty bearers (UAO and Executive Engineer). On average, ten farmers including the pump owners of the irrigation scheme from each AWD group took part in the discussion. The FGDs and KIIs were conducted using a predetermined questionnaire encompassing the relevant issues and problems.

\section{Results}

\subsection{Stakeholder influence}

Initial efforts have been made to incorporate AWD into national policies and structures, explicitly the National Agriculture Policy (NAP) 2018 and Integrated Minor Irrigation Policy (IMIP) 2017. The stakeholder assessment focused on their specific contribution to the AWD dissemination process. The dissemination approaches employed at the national level include important policy steps, capacity building, and multi-stakeholder communication and cooperation, which are all considered important elements of the dissemination process. Still, effective mechanisms are required to successfully disseminate AWD in Bangladesh (Hoffmann, Gerster-Bentaya, Chris, \& Lemma, 2009). 
The Upazila Irrigation Committee (UIC) was mentioned as a powerful stakeholder group. The UIC was composed of an Upazila Nirbahi Officer (UNO) as the chair, engineers of BADC/BMDA as member secretaries, and the UAP and managers of the Rural Electricity Board (REB) and the Power Development Board (PDB) as members. These players are strongly influential in the approval and control of irrigation pumps ${ }^{2}$. Additionally, the Upazila Chairman, the local member of parliament, and the officials of the Bangladesh Rural Development Board had some sort of informal influence in the AWD implementation process.

Among these actors, farmers who were applying AWD, pump owners, and the UIC were the three most powerful influencers for outscaling AWD. The first two stakeholders directly negotiated the pumping cost and operation. The UIC, in principle, was in charge of approving pump installation and pump operation licenses, and monitoring irrigation management schemes to make sure they comply with relevant irrigation policies and laws.

Further, the UAO and REB/PDB managers were reported to have high influence facilitating deep tube well pump installation and operation. Specifically, the UAO and the BADC Engineer jointly investigated pump owners' applications; the BADC Engineer would then issue the requested license upon UIC's approval. The REB/PDB managers provided permission for electricity connection and supply to the electricity-operated pumps, while the UAO facilitated this process. By following the formal process for installation of the deep tube well, service providers avail of electricity subsidies.
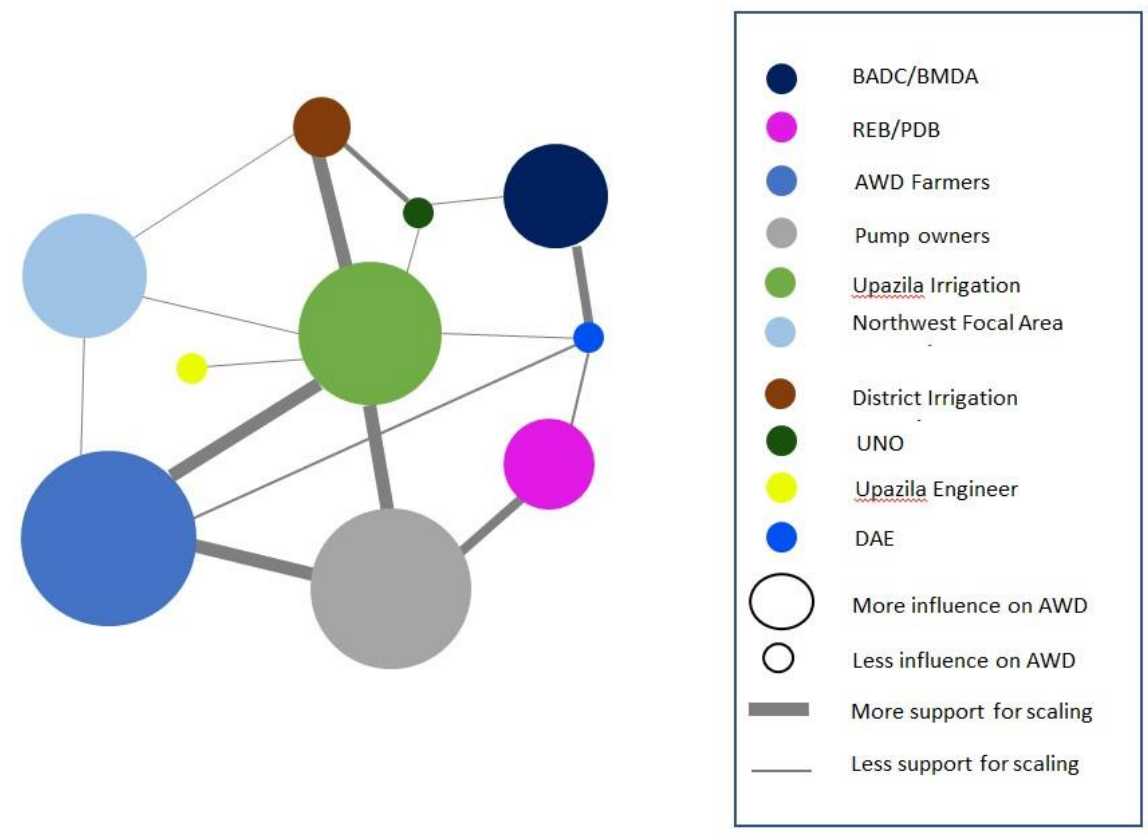

Figure 2: Multiplex Net-Map including relation linkages and power linkages. Each coloured circle represents a stakeholder, the size of the circle corresponds to the degree of influence on carrying out AWD, and the size of the linkage corresponds to the degree of support. 


\subsection{Irrigation service schemes}

To understand the contextual factors affecting the outscaling of AWD, it is essential to investigate the current mechanism in which irrigation for paddy rice farming is operated and managed. The research explored the current water pricing schemes and payment methods in the selected catchment areas in the surveyed areas.

The method of pricing water significantly affects water efficiency in irrigation. In Bangladesh, shallow tube well pump owners usually provide irrigation water on the basis of a fixed seasonal cost for each plot of land regardless of the water volume. A pump owner makes his/her own irrigation schedule starting with one plot then to the adjacent plot until reaching the last plot in his/her catchment area. This fixed-charge scheme is the most commonly practiced by the farmers interviewed in this study. The former is employed by all owners of electric pumps; while the latter is widely adopted among owners of diesel-operated machines. The only exception was in Rajshahi district (Rajshahi division), where owners of diesel-operated machines operate under the area-based fixed contract system.

Under the system of the area-based fixed contract, pump owners charge farmers for the cost of electricity/diesel, lubricant, management and supervision based on the size of their land. A farmer negotiates with a pump owner to determine a fixed rate to irrigate the entire plot throughout a season regardless of the actual amount of water that will be delivered to the field. Payment is made either once or in several instalments during the season.

Under the machine rental system, a farmer pays for pump rental and fuel separately. S/He pays a rental amount to the machine owner which is fixed for the whole season depending on the size and characteristics the land, and supplies diesel and lubricant to the machine owner every time water is pumped to her/his land. The cost of fuel and lubricant is proportionate to the time of pumping, meaning the less water pumped, the less the cost. Similar to the fixed contract system, farmers under the rental scheme can pay the total amount of rent at once or pay different instalments. This system gives farmers more incentive to use water more efficiently because they can save on costs for fuel and lubricant for pumping.

To effectively encourage efficient water use, all pumping costs should be proportionate to the volume of water delivered. Such a volumetric charging system has been practised in the Barind area and managed by the Barind Multipurpose Development Authority (BMDA) using prepaid meters. As described by Rashid and Hossain (2009), a pumping machine in each area is fitted with a digital meter which pumps water automatically when a farmer's card is inserted and stops when the card is finished or withdrawn. A farmer gets his/her reusable card charged with the desired amount of money by a dealer using a mobile vending unit (MVU) equipped by the BMDA. This scheme motivates farmers to use water only as needed to maximise cost-effectiveness. By July 2018, over 7,000 pumps had been connected to prepaid meters to operate irrigation upon farmer's demand and payment (BSS, 2018). 
This study reveals a variant of this system wherein a group of 100 farmers buy prepaid irrigation cards at the rate of BDT 95/hour from BMDA and self-manage irrigation among members. They recruit a manager and elect their chairman, secretary and cashier to the group's pumping activity. The group collect a fixed water charge at BDT 7,500/hectare from each group member and retain a reserve fund to buy prepaid cards as and when required. In 2018, this group saved BDT 40,000 after all costs including electricity fees. This provides evidence that prepaid card systems managed by wellorganized farmers' groups would be conducive for efficient use of irrigation water.

Regarding water usage, farmers under the fixed contract system consumed more water than those under the other irrigation schemes. It was evident during FGDs that the fixed contract usually led to higher water consumption since farmers wished to get as much water as they could out of the fixed paid amount. In contrast, those who participated in the other two systems would more carefully manage their water use and practice water saving techniques, such as alternate wetting and drying (AWD). During the FGDs, the farmers under the machine rental system were more conscious about water use and management compared to their counterparts in the fixed contract system because they had to purchase diesel for water delivery. They also usually made high bunds around their plots to retain water.

Literature revealed that prepaid irrigation demonstrated a high level of water efficiency, probably the highest among these three schemes (Pandey, 2020). Farmers paid by the hour of irrigation; thus, they took only the amount needed to maximize the benefit. It was reported that it took less than 2,300 litres of water to produce one $\mathrm{kg}$ of Boro rice when irrigated by prepaid meter, $34 \%$ lower than the amount of 3,400 litres required under other schemes (Zaman, 2019). As less water was wasted, more plots were irrigated than under the other methods. It was estimated that the command area when served by prepaid meters expanded by 22\%, benefiting $13 \%$ more farmers (Zaman, 2013).

However, an impact assessment jointly conducted by a group of researchers at IRRI and Tufts University discovered a practice in which the charge-by-hour system using prepaid cards was turned into a charge-by-area scheme in Rajshahi district. Specifically, some farmers did not own individual prepaid cards given the complex registration and initial investment costs required to apply for one. Instead, they re-rented irrigation services from a tube-well operator. This operator owned a card then organized irrigation among a group of farmers. He/she calculated the average cost for pumping to each acreage of land for the season then charged farmers based on that rate. This practice was due to several factors including the cost and time to acquire a card, the difficulty in coordinating farmers when using the pumps, and the unfairness in pricing because farmers whose land were far from the wells and suffered water loss during conveyance paid the same price with those in closer proximity (Chakravorty, Dar, \& Emerick, 2020). Under this group management mechanism, farmers were no longer concerned about the duration of pumping or volume of water use because they paid a fixed cost for the entire season. 


\subsection{Irrigation costs}

Regarding pricing, the rates of irrigation reported by the case studies are presented in Table 2 below.

Table 2: Irrigation costs under different schemes

\begin{tabular}{|l|r|r|}
\hline \multirow{2}{*}{ District } & \multicolumn{2}{|c|}{ Irrigation cost (BDT/ha) } \\
\cline { 2 - 3 } & Fixed contract & Machine rental \\
\hline Rangpur & 11,386 & 21,962 \\
\hline Nilphamari & 12,147 & 13,548 \\
\hline Gaibandha & 12,891 & \\
\hline Panchagarh & 12,766 & \\
\hline Kurigram & & 13,582 \\
\hline Lalmonirhat & & 13,797 \\
\hline Thakurgaon & 15,562 & 15,456 \\
\hline Rajshahi & 16,688 & \\
\hline Naogaon & $\mathbf{1 3 , 5 7 3}$ & $\mathbf{1 5 , 6 6 9}$ \\
\hline Average & & \\
\hline
\end{tabular}

On average, farmers under the fixed contract system paid approximately BDT 13,500 to irrigate one hectare of land for a season; while those who followed the pump rental scheme gave nearly BDT $16,000 /$ ha to the machine owner including the diesel costs. Pumping rates varied widely. The rate for a farmer was influenced by the time of payment, soil type, the elevation of the plot, distance from the pump to the field, and the relationship between him/her and the pump owner to negotiate a price.

On the other hand, the charges that were imposed on farmers under the prepaid system were fixed and centrally managed by the BMDA. Zaman's study (2019) reported that the irrigation cost was fixed at BDT 5,440/ha, 51\% lower than the estimated cost under a non-prepaid system (BDT 11,000/ha) in the Barind area. All farmers paid the same volumetric rate regardless of the location or characteristics of the fields, however, the losses are greater for those fields further away due to conveyance losses during the transportation of water in canals. Farmers decided which amount to charge into their cards at any time but the more common practice was that the tube well owner managed the prepaid card and did not pass on the benefits of volumetric measurement to the farmers. A registration fee of BDT 150 was required for farmers to get their individual cards (Chakravorty, Dar, \& Emerick, 2020).

The operation of the prepaid system was automatically administered and centrally managed by the BMDA, while the other two schemes were run by individual pump owners. In the case of fixedcontract irrigation, machine owners pumped water to all plots in their catchment areas in an ordered manner, meaning the fields were irrigated one after another. When in their turns, farmers could get unlimited water without any concerns about the irrigation duration or water reserves for the next users. Canal maintenance was neither their duty nor was it the responsibility of pump owners. For these 
reasons, farmers who were surveyed seemed to prefer this system to the machine rental scheme. Literature supported this statement. Johansson (2000) conducted a study on 12 million hectares of irrigated land and found that in over $60 \%$ of the cases, water was charged with a fixed rate on a perhectare basis. Similarly, Amin (2007) also reported that the area-based fixed contract scheme was more favoured by farmers.

To the contrary, the interviewed pump owners favoured the machine rental scheme better due to the convenience in operation. They had to manage neither fuel purchase nor pumping organization, they simply operated the pumps when farmers brought in diesel. Under this system, farmers paid for canal maintenance, thus pump owners did not have to bear such cost. Plus, the use of diesel allowed them to operate pumps even when electricity supply was disrupted, which often happened in the region. The disadvantage, however, lies in the requirement for a meter scale to gauge the use of diesel given by one farmer before the next farmer used her/his diesel, which must be accurately read and reported. An alternative method was to charge by the duration of water delivery given that water flow was reasonably constant in the canals.

The prepaid system seems to be the most advantageous among these schemes. BMDA bore the costs of system instalment, maintenance, and operation, which facilitated the participation of farmers. All transactions were conducted and monitored systematically using machines, thus there was no scope for deception in service provision or payment. Information on service usage and costs were disclosed to farmers, giving them control of their irrigation activities. Farmers easily operate the meters and were able to pay the fee and get water anytime using their cards. Overall, this system mechanized irrigation operation and gave autonomy to farmers to manage the time and cost of irrigation, thus increasing input efficiency.

\subsection{Economic and environmental effects of AWD technology}

In light of the above water pricing analysis, the research further investigated the effect of AWD on irrigation practices that farmers experienced. We compare the results in irrigation frequency and costs in rice production between AWD and non-AWD practices in Rangpur division during Boro seasons in 2018 and again in 2019. Hereinafter, the practices of rice cultivation with AWD technology and with conventional irrigation methods are referred to as AWD farming and non-AWD farming respectively.

Results show that less irrigation was required by AWD farmers than by their non-AWD counterparts. Data collected from 577 farmers in Rangpur division shows that AWD fields required less number of times of irrigating the field than non-AWD fields by $30.8 \%$. On average, the AWD farmers required 16.9 pumping times while this figure for non-AWD farmers is 24.5 times. The average times of irrigation by location are compared between AWD and non-AWD groups in Table 3, each followed by its standard deviation in brackets. It shows a consistent pattern in which the number of pumping times when AWD was applied was lower than in non-AWD cultivation across all locations, the difference was between 19-40\%. Figure 2 illustrates these comparisons. When the total averages were compared 
between AWD and non-AWD farmers, we found significant differences between both the number of irrigation times and the total cost of irrigation/ha at $\mathrm{p}<0.01$ using $\mathrm{t}$-test analysis.

Table 3: Comparison of the number of pumping times and irrigation cost between AWD and Non-AWD farmers

\begin{tabular}{|c|c|c|c|c|}
\hline \multirow{2}{*}{ Location } & \multicolumn{2}{|c|}{ AWD farmers } & \multicolumn{2}{c|}{ Non-AWD farmers } \\
\cline { 2 - 5 } & $\begin{array}{c}\text { Number of irrigation } \\
\text { times }\end{array}$ & Total irrigation cost/ha & $\begin{array}{c}\text { Number of irrigation } \\
\text { times }\end{array}$ & Total irrigation cost/ha \\
\hline Rangpur & $16.54(1.65)$ & $18,385.33(6,941.24)$ & $26.67(2.5)$ & $26,420.01(7,572.69)$ \\
\hline Kurigram & $15.92(1.44)$ & $10,933.7(5,823.65)$ & $26.57(1.81)$ & $18,500.8(5,012.63)$ \\
\hline Nilphamari & $18.2(3.41)$ & $12,012.86(1,471.16)$ & $23.18(2.68)$ & $17,904.76(3,109.21)$ \\
\hline Gaibandha & $10.4(0.55)$ & $12,053.59(177.58)$ & $22.5(0.71)$ & $14,983.06(18.9)$ \\
\hline Lalmonirhat & $13.83(0.75)$ & $13,571.35(2,337.63)$ & $20.5(0.71)$ & $14,474.2(2,654.76)$ \\
\hline Thakurgaon & $17(2.8)$ & $15,682.31(7,264.13)$ & $21(1)$ & $14,550.36(3,004.44)$ \\
\hline Panchagarh & $21(0.82)$ & $12,004.93(690.15)$ & 26() & $15,808()$ \\
\hline Total Average & $\mathbf{1 6 . 9 2 ( 3 . 1 9 )}$ & $\mathbf{1 3 , 8 7 8 . 4 2 ( 5 , 3 9 9 . 7 7 )}$ & $\mathbf{2 4 . 4 6 ( 3 . 0 4 )}$ & $\mathbf{1 9 , 5 0 3 . 1 9 ( 2 5 2 . 6 1 )}$ \\
\hline
\end{tabular}

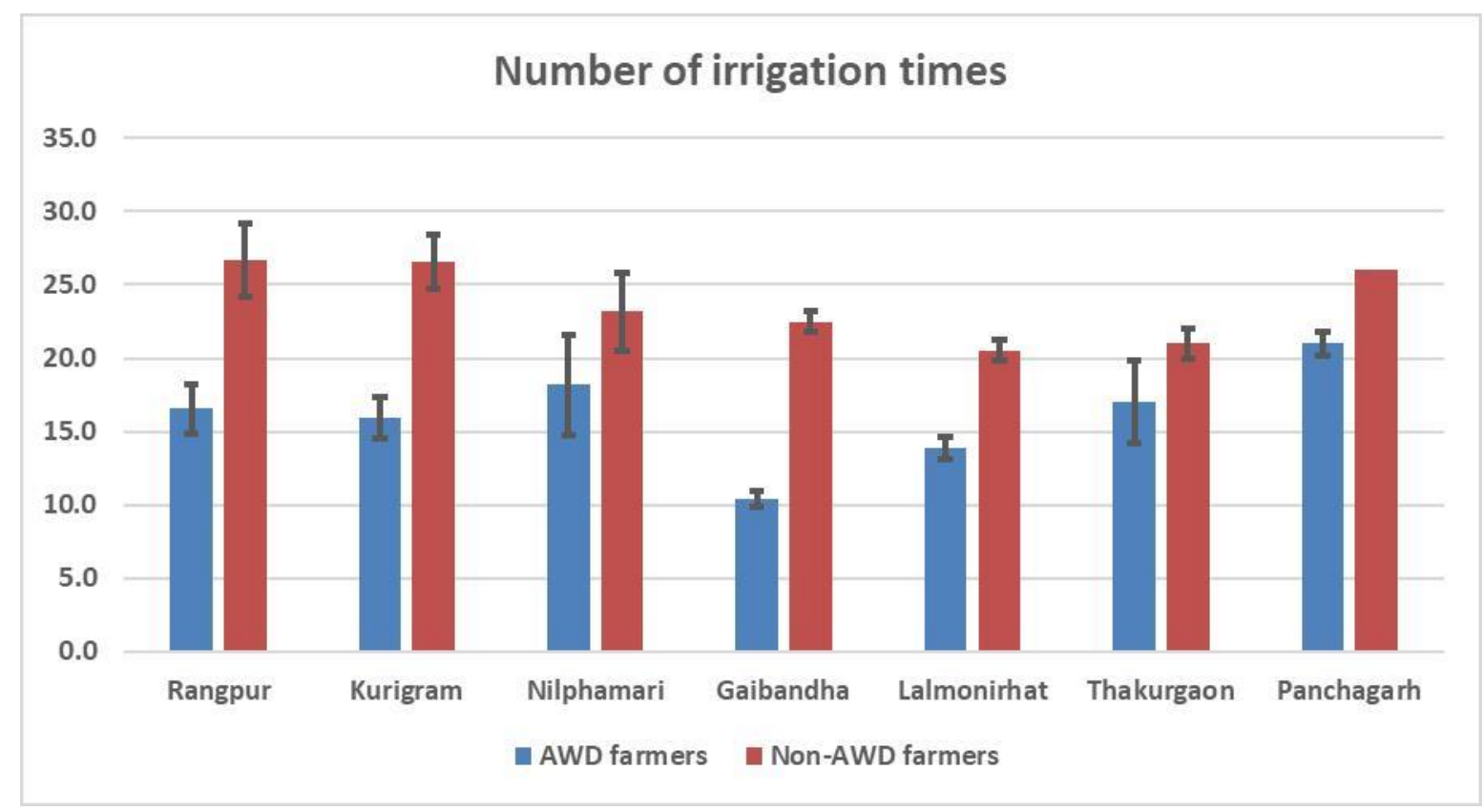

Figure 3: Averages and standard deviations of irrigation times in surveyed locations

Table 3 also describes the unit irrigation cost by ha, which consists of payment to pump owner and fuel cost. Generally, AWD farmers paid BDT10,900-18,400 per irrigated hectare while the non-AWD farmers spent BDT14,400-26,400 per ha. Except for Thakurgaon district, AWD reduced irrigation cost by $6-41 \%$. The average irrigation costs and standard deviations by location are depicted in Figure 4 below. 


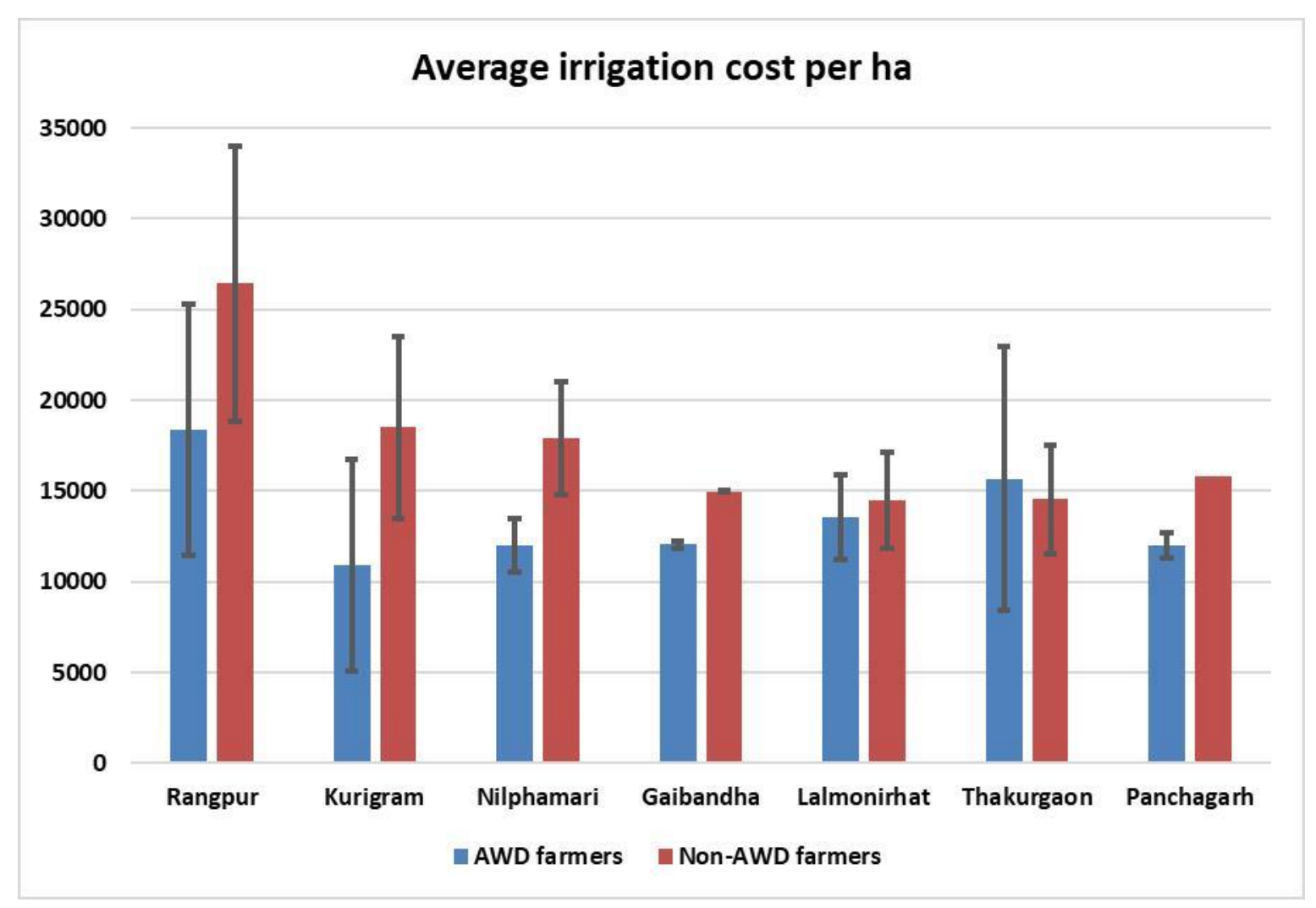

Figure 4: Averages and standard deviations of irrigation costs in surveyed locations

Considering the entire sample of all seven districts, the AWD farmers paid BDT 13,878 to have one hectare of land irrigated throughout one Boro season, $28.8 \%$ less than the amount paid by the nonAWD farmers at BDT 19,503 per ha.

Similarly, the FGD in Rajshahi and Naogaon districts of Naogaon division reported that AWD farmers had on average $26.5 \%$ fewer times of pumping and saved $20 \%$ in irrigation costs. The case studies with 72 farmers in five districts in Mymensingh and Sherpur divisions generated a consensus that AWD had positive effects on income through reduced production costs. On average, continuously flooded fields in these locations took four more pumping times than AWD plots. The average duration of pumping to AWD plots per season was 66.7 hours/ha, one-third of the pumping time to conventional fields (101.3 hours/ha). Similar findings were found in other studies that AWD could reduce the cost of irrigation by reducing pumping costs and fuel consumption (Lampayan, Rejesus, Singleton, \& Bouman, 2015). Less irrigation was associated with the reduction of irrigation cost by $12 \%$ to $15 \%$ implying a clear advantage of AWD irrigation to the resource-poor farmers (Alam, Islam, Abdus, \& Islam, 2009).

The effects of AWD technology in water use was further investigated in the prepaid irrigation scheme and the area-based payment scheme. Random measurement in the first 70 days of the season reported that water levels in AWD fields were $31 \%$ lower than in non-AWD fields. To the contrary, there was no significant difference in water levels under the fixed-rate contract irrigation systems (Chakravorty, Dar, \& Emerick, 2020). 
This pattern was also found in cost and profit analysis. The fact that water was charged marginally encouraged AWD farmers to regulate the amount of water pumped into their fields, leading to a saving of over BDT 900 in irrigation cost, 17\% lower than the amount paid by non-AWD farmers. This effect was not found among those who paid fixed prices. AWD was reported to increase cardholders' profits by almost BDT 1,900, $7 \%$ higher than non-AWD counterparts while having no impact on the profits of non-cardholders (Chakravorty, Dar, \& Emerick, 2020).

A study in four Upazilas namely Trishal, Fulbaria, Nakla, and Nalitabari in Mymensingh area by Saha (2017) found that in addition to irrigation and cost reduction effects, AWD also enhanced water productivity of rice farming, which is the yield of rice produced using one meter cubed of water. Data analysis showed improvement of water productivity in four areas when AWD was applied compared to conventional methods by an average of $68.7 \%$ (absolute increase by $0.21-0.67 \mathrm{~kg} / \mathrm{m} 3$ ). It was discussed that this improvement in water efficiency, in the condition of no water loss, could save a significant amount of groundwater, contributing to the conservation of this scarce resource. These are promising findings; however, more research should be conducted on the effect of AWD on groundwater levels because these initial findings were based on relatively small sample sizes.

\subsection{Factors stimulating farmers' take-up of AWD technology}

FGDs conducted during this project revealed that the majority of farmers acknowledged that AWD technology was effective for saving water and reducing production costs; however, it would not be so beneficial unless the irrigation cost was charged by unit of use. They suggested removing the system of fixed electricity billing to take advantage of AWD irrigation technology.

The experiments conducted by Chakravorty et al. (2020) supported this finding. They found that farmers who participated in the prepaid irrigation scheme were more motivated to apply AWD deliberately. The research team monitored farmers' willingness to purchase the AWD pipe at different prices. Observation of the farmers on fixed-cost irrigation schemes shows that the higher the cost of AWD pipe, the more price-sensitive they became. To the contrary, farmers on volumetric/hourly pricing schemes were less sensitive to the increase in price, meaning they would keep buying the AWD pipe despite it becoming more expensive because they would still benefit from the reduced irrigation cost. Generally, the use of prepaid irrigation cards resulted in an increase in AWD adoption rate by approximately $10 \%$ at all price levels. The difference between the control group of farmers and those under prepaid card treatment varied from one village to another but was statistically significant in all studied villages.

FGD in Mymensingh division suggested other incentives to farmers' adoption of AWD technology. First, AWD was more suitable for paddy land at high or medium altitude because the low-land areas could not naturally drain. Secondly, AWD was not widely known among farmers, so the local authority such as the Department of Agricultural Extension should increase farmers' awareness about the impact of water wastage and introduce AWD technology at the grassroots level. The media would be an effective channel to disseminate about the benefits and how-to of AWD as well. 


\section{Discussion/Conclusion}

The constraints of AWD adoption in Bangladesh were mainly institutional in nature. First, the most common arrangement for payment of water in which a fixed seasonal rate is applied does not provide farmers with an incentive for reducing water consumption. The reality is quite the opposite. Pump owners do not pass on economic benefits from the saving in water and energy. Negotiating a changed arrangement would require a collective agreement of all farmers in a scheme to implement AWD. Development NGOs made efforts to facilitate farmer organization and influence the uptake of AWD by facilitating farmers' forums and organizing workshops for dialogue with pump owners. However, pump owners, especially those using subsidized electricity, were not very willing to change. The second constraint relates to a lack of organizational capability for promoting AWD nationally. AWD has been successfully promoted at local levels by development organizations working with the DAE, but it was not fully implemented as a national campaign.

As suggested by the findings, farmers, pump owners, and leaders and members of the UIC are the primary stakeholders that should be consulted during the planning and dissemination of AWD. Engaging these stakeholders (and others as resources allow) in the early stages of decision-making is critical. The suggested methods of stakeholder engagement are as follows:

- Awareness-raising promotional workshops/meetings

- Training using participatory learning tools, field demonstrations, field days, exposure visits, monitoring and evaluation

- Advocacy training, facilitation of meeting with UIC, voicing through a memorandum to the chair and secretary of UIC

- Policy advocacy workshops/events

Crucially, the government has an important role to play in establishing an institutional environment that encourages exchange between producers, practitioners, policy-makers, and researchers to facilitate a more bottom-up decision-making process.

The analysis of current irrigation schemes shows that the fixed-cost systems do not particularly increase the effectiveness in practising AWD. It is then recommended that AWD is promoted in areas where the volumetric charging system for irrigation is in place and properly operated, meaning that farmers use individual cards. The way that it is practised now in some areas wherein the volumetric charges are turned into fixed rates is neglecting the benefits offered by having a volumetric meter system. The dissemination of AWD should be accompanied by the introduction of the prepaid irrigation system and supported by well-functioning management and governance. This calls for the engagement of central and local governmental authorities (BMDA, DAE, etc.) as well as relevant institutions (such as the UIC).

To facilitate the establishment and functioning of the prepaid card system, efforts should be spent to promote farmers' ownership of the irrigation cards. Among the barriers that farmers face in acquiring such prepaid cards, the main issues lie in the application procedure and fee. Hence, a project or scheme that provides farmers with technical and financial assistance in the initial application process 
is highly recommended. While normally such an initiative requires a governmental role, there is an opportunity for the participation of national/international NGOs, and the private sector.

\section{Acknowledgements}

The authors are grateful to Mr Shamiran, Coordinator of CCDB for his contribution and support to this study. The authors further express their gratitude to the Northwest Focal Area Network, local authorities, and the farmers for their participation, support, and technical assistance for the research.

This work was funded by USAID Office of Global Climate Change and is implemented as part of the CGIAR Research Program on Climate Change, Agriculture and Food Security (CCAFS), which is carried out with support from the CGIAR Trust Fund and through bilateral funding agreements. The study further received funding from the Climate and Clean Air Coalition (CCAC) within the project "Mitigation Options to Reduce Methane Emissions in Paddy Rice" also implemented by IRRI. The authors declare no potential competing interest.

\section{Notes:}

${ }^{1}$ Computed using data from U.S. Environmental Protection Agency’s (U.S. EPA’s) Global Anthropogenic Emissions of Non-CO2 Greenhouse Gases: 1990-2030 report. https://www.epa.gov/climate-change

${ }^{2}$ Bangladesh Integrated Minor Irrigation Policy 2017-18. Retrieved from http://badc.portal.gov.bd/sites/default/files/files/badc.portal.gov.bd/page/c23bdffd_22fd_4f15 8fc4 b1fc7a91a3 6a/d5a84d165253f9e02d6190b5d28b1340.pdf

\footnotetext{
${ }^{3}$ Although the authors followed international and national protocol guiding ethical research with human subjects, at the time the research was conducted, the International Rice Research Institute did not have an institutional review board. However, since the establishment of the IRRI Research Ethics Committee on October 19, 2018, ethics approval has been granted for similar studies under the IREC Protocol Number 2020-0013-A-2016-70.
} 


\section{References}

Alam, M., Islam, M., Abdus, S., \& Islam, M. (2009). Economics of Alternate Wetting and Drying Method of Irrigation: Evidences from Farm Level Study. The Agriculturists, 7(1\&2):82-95.

Amin, M. (2007). Water pricing in different minor irrigation systems - Thesis. Dhaka: Institute of Water and Flood Management (IWFM), Bangladesh University of Engineering and Technology (BUET).

Bangladesh Bureau of Statistics. (2015). Statistical Yearbook of Bangladesh. Dhaka: Bangladesh Ministry of Planning.

Bangladesh Ministry of Finance. (2014). Bangladesh Economic Review 2014. Dhaka: Ministry of Finance.

Bangladesh Rice Research Institute. (2017). Bangladesh Knowledge Bank. Retrieved from http://knowledgebank-brri.org/

Bosworth, B., Cornish, G., Perry, C., \& Van, S. F. (2002). Water charging in irrigated agriculture. Wallingford: HR Wallingford Ltd.

Bouman, B. T. (2001). Field water management to save water and increase itsproductivity in irrigated lowland rice. Agricultural Water Management, 49(1):11-30.

BSS. (2018, July 22). Barind Multipurpose Development Authority - Tk 3,454cr projects being implemented in Rajshahi, Rangpur divisions. Retrieved from The Independent BD: http://m.theindependentbd.com/printversion/details/158873

Chakravorty, U., Dar, M., \& Emerick, K. (2020). Impact of alternate wetting and drying on farm incomes and water savings in Bangladesh - 3ie Impact Evaluation Report 108. New Delhi: International Initiative for Impact Evaluation (3ie).

FAOSTAT. (2012). Food and Agricultural Commodities Production 2010. Retrieved from Food and Agriculture Organization of the United Nations: http://faostat. fao.org/site/339/default.aspx.

FAPRI. (2009). The Agricultural Outlook 2009. World Rice. . Food and Agricultural Policy Research Institute. Available at http://www.fapri. iastate. edu/outlook/2009/. .

Hasan, K., Habib, A., Abdullah, M., Bhattacharjee, D., \& Islam, S. (2016). mpact of Alternate Wetting and Drying Technique on Rice Production in the Drought Prone Areas of Bangladesh. Indian Research Journal of Extension Education, Vol. 16, No. 1, pp. 39-48 .

Hoffmann, V., Gerster-Bentaya, M., Chris, A., \& Lemma, M. (2009). Basic Issues and Concepts. In Handbook: Rural Extension (p. 119). Weikersheim: Margraf Publisher.

Hossain, S. M. (2013). Performance of Raised Bed Irrigation in Comparison to AWD and Flood Irrigation for Boro Rice. Journal of Agriculture and Veterinary Science, Vol. 5, No. 6, pp. 8285. . 
Husain, M. M., Kabir, M. H., Alam, M. S., K., K. A., \& M., I. M. (2009). Water Saving Irrigation in Rice Cultivation with Particular Reference to Alternate Wetting and Drying Method: An Overview. The Agriculturists, Vol. 7(1 and 2), pp. 128-136.

Johansson, R. C. (2000). Pricing Irrigation Water: A Literature Survey. Washington DC, 80pp: World Bank.

Lampayan, R., Rejesus, R., Singleton, G., \& Bouman, B. (2015). Adoption and economics of alternate wetting and drying water management for irrigated lowland rice. Field Crops Research, Volume 170, Pg. 95-108.

Maclean, J. D. (2002). Rice almanac (Third Edition). Philippines: IRRI, WARDA, CIAT and FAO.

Madi, M. O. (2009). Farm-level perspectives regarding irrigation water prices in the Tulkarm district, Palestine. Birzeit, The West Bank, Palestine: Institute of Environmental and Water Studies, Birzeit University.

Miah, H. (2009). Effects of AWD technology on grain weight. The 4th World Congress on Conservation Agriculture. New Delhi.

Ministry of Agriculture of Bangladesh. (2013). National Agriculture Policy. Dhaka: Ministry of Agriculture of Bangladesh.

Mishra, H., Rathore, T., \& Plant, R. (1990). Effects of intermittent irrigation on groundwater table contribution, irrigation requirement and yield of rice in Mollisols of the Terai region. Agricultural Water Management, Vol. 18, No. 3, pp. 231-241.

Nalley, L., Linquist, B., Kovacs, K., \& Anders, M. (2015). The Economic Viability of Alternative Wetting and Drying Irrigation in Arkansas Rice Production. . Agronomy Journal, pp. Volume 107, Issue 2. .

Pandey, S., Yadav, S., Hellin, J., Balié, J., Bhandari, H., Kumar, A., \& Mondal, M. K. (2020). Why Technologies Often Fail to Scale: Policy and Market Failures behind Limited Scaling of Alternate Wetting and Drying in Rice in Bangladesh. Water, 12(5), 1510.

Price, A. H., Norton, G. J., Salt, D. E., Ebenhoeh, O., Meharg, A. A., Meharg (nee Reiff), C., \& Davies, W. J. (2013). Alternate wetting and drying irrigation for rice in Bangladesh: Is it sustainable and has plant breeding something to offer? Food Energy and Security, Vol. 2(2), pp. 120-129.

Price, A. H., Norton, G. J., Salt, D. E., Ebenhoeh, O., Meharg, A. A., Meharg (nee Reiff), C., \& Davies, W. J. (2013). Alternate wetting and drying irrigation for rice in Bangladesh: Is it sustainable and has plant breeding something to offer? Food Energy and Security, Vol. 2(2), pp. 120-129.

Rahman, M. S., \& Angelsen, A. (2011). Comparison between Irrigation Payment Systems and Probability of Using Water Saving Technology. Journal of Economics and Sustainable Development, pp. Vol. 2, No. 10. 
Rashid, A., \& Hossain, I. (2009). Irrigation Management System of BMDA: an Innovative Approach. . Conference: 2nd International Conference on Planning, Architecture and Civil Engineering (ICPACE). Rajshahi : Rajshahi University of Engineering \& Technology.

Rejesus, R., Palis, F., Rodriguez, D., Lampayan, R., \& Bouman, B. (2011). Impact of the alternate wetting and drying $(A W D)$ water-saving irrigation technique: evidence from rice producers in the Philippines. Food Policy 36, 280-288.

Saha, M. (2017). A comparative study on alternate wetting and drying and conventional methods of irrigation for producing Boro rice in Mymensingh region - Thesis. Mymensingh: Department of Agricultural Economics, Bangladesh Agricultural University.

Sattar, M., Rashid, M., Hossain, H., Khan, A., Parveen, S., Roy, D., \& Mahmud, H. (2009). AWD Technology for Water Saving in Boro Rice Production for the Selected Locations. National workshop on AWD technology for rice production in Bangladesh, (pp. 1-14).

Schiffer, E. (2007). The power mapping tool: A method for emperical research on power relations. Washington D.C.: Internatinal Food Policy Research Institute. Discussion Paper No. 703.

Shiffer, E., \& Waale, D. (2008). Tracing Power and Influence in Networks: Net-map as a tool for research and strategic network planning. Washington D.C.: International Food Policy Research Institute. Discussion Paper No. 772.

Tan, X., Shao, D., Liu, H., Yang, F., Xiao, C., \& Yang, H. (2011). Effects of alternate wetting and drying irrigation on percolation and nitrogen leaching in paddy fields. Paddy and Water Environment, 11, 381-395.

Zaman, A. (2013). Replication of the Barind Model to Muhuri Irrigation Project. Moving from Water Problems to Water Solutions: Research Needs Assessment for the Eastern Gangetic Plains. International Workshop held at the National Agricultural Science Complex (NASC). New Delhi: Indian Council of Agricultural Research (ICAR).

Zaman, A. (2019). Participatory Irrigation Management: Barind Model a New Sustainable Initiative. Universal Journal of Management, 7.6 (2019) 220 - 228. doi: 10.13189/ujm.2019.070603. 